\title{
A Comparative Investigation of Lead Sulfate and Lead Oxide Sulfate Study of Morphology and Thermal Decomposition
}

\author{
Seyed Ali Akbar Sajadi \\ Sharif University of Technology, Institute of Water \& Energy, Tehran, Iran \\ E-mail:sajadi@sharif.ac.ir \\ Received November 30, 2010; revised March 3, 2011; accepted March 20, 2011
}

\begin{abstract}
The compound lead oxide sulfate $\mathrm{PbSO}_{4} \cdot \mathrm{PbO}$ was prepared in our laboratory. The Thermal behavior of $\mathrm{PbSO}_{4}$ was studied using techniques of Thermogravimetry under air atmosphere from 25 to $1200^{\circ} \mathrm{C}$. The identity of both compounds was confirmed by XRD technique. Results obtained using both techniques support same decomposition stages for this compound. The electron microscopic investigations are made by SEM and TEM. The compound is characterized by XRD and the purity was determined by analytical Methods. Also a series of thermogravimetric analysis is made and the ideal condition is determined to convert this compound to pure lead oxide.
\end{abstract}

Keywords: Lead Oxide Sulfate, Lead Sulfate, XRD, Thermal Analysis, Thermogravimetry, TGA

\section{Introduction}

Lead compounds are used in different industries worldwide due to their chemical and physical characteristics [1-6]. One of the most important characteristics of the lead is its reactions with acids and bases as well as with air, which are well-known as oxidation. In consequence of these kinds of reactions compounds like "lead (II) oxide, lead (IV) oxide, sulfate, lead carbonate, lead nitrate as well as alkaline lead acetate" have been produced. Some are the end product of a desired process but most of them are undesired byproducts and are known as disturb compounds $[8,9]$.

Lead (IV) oxide is one of the most important compounds used in lead-acid batteries, which are produced daily all over the world $[5,7]$.

The goal of this work was to investigate the morphology and crystal size of $\mathrm{PbSO}_{4}$. $\mathrm{PbO}$ and study of thermal properties of lead sulfate in different temperature conditions. Pure lead (II) oxide has been reported to be the final product of thermal decomposition process of number of different lead compounds [10-12]. The Morphology of these compounds was also reported [13-15].

\section{Experimental}

\subsection{Materials and Equipment}

Lead oxide sulfate was prepared in this laboratory as described in this paper. Alkaline lead (II) acetate purchased from Fluka (Art. No.: 15317). $\mathrm{H}_{2} \mathrm{NSO}_{3} \mathrm{H}$ amido sulfonic acid purchased from Merck (Art. No.: 10010 30250).

TGA: Thermogravimeter, Mettler TG50, coupled with a TA processor.

XRD: X-Ray diffractometer D 5000, Siemens, Kristalloflex.

SEM: scanning electron microscope SEM (REMJEOL-JSM-840).

TEM: transmission electron microscope (EM-Hitachi, H-600).

\subsection{Preparation of Lead Oxide Sulfate $\mathrm{PbSO}_{4} \cdot \mathrm{PbO}$}

$2.0284 \mathrm{~g}$ alkaline lead (II) acetate was added to $10 \mathrm{ml}$ $\mathrm{H}_{2} \mathrm{NSO}_{3} \mathrm{H}$ solution $\left(0.3236 \mathrm{~g}\right.$ solved in $\mathrm{H}_{2} \mathrm{O}$ ). It was produced a clear solution. This solution was transferred 
in a quartz ampoule. The ampoule was then sealed carefully. This was heated in a sealed tube furnace at 130 for about 20 hours and then 4 hours at 140. The ampoule was cooled to room temperature. From solution is formed needle-shaped crystals (about $0.5 \mathrm{~mm}$ long). To clean the product it was filtered and several times washed with water and alcohol. Afterwards was dried in a desiccator over silica gel at $25^{\circ} \mathrm{C}$.

\subsection{X-Ray Diffraction of $\mathrm{PbSO}_{4}$ and Lead Oxide Sulfate $\mathrm{PbSO}_{4} \mathrm{PbO}$}

The lead oxide sulfate sample was prepared for X-ray using Bedacryl and exposed with $\mathrm{CuK} \alpha 1$ radiation for two hours. Figure 1 shows the XRD diagram of the compound $\mathrm{PbSO}_{4} \cdot \mathrm{PbO}$.

\subsection{Electron Micrographs Investigations of $\mathrm{PbSO}_{4}$ and $\mathrm{PbSO}_{4} \mathrm{PbO}$}

The morphologic investigations of lead oxide sulfate and lead sulfate that is the goal of this work, were accomplished by an electron microscope SEM(REM-JEOLJSM-840). The preparation of the samples consisted of coating of the surface with gold steam during 2 to 4 minutes (Figures 3 and 4).

The second series of electron microscopic investigation with TEM equipment were accomplished (EM-Hitachi, H-600). The sample was prepared as follows. The white powdery sample was coated first with a thin coal film. This film was then treated with HF acid from the surface and investigated in the TEM equipment. The applied enlargement was $20000 \times($ Figure 5).

\subsection{TGA Analysis of Lead Sulfate $\mathrm{PbSO}_{4}$}

$8.197 \mathrm{mg}$ of $\mathrm{PbSO}_{4}$ were weighted in a standard container from corundum. This sample was heated $\left(5^{\circ} \mathrm{C} / \mathrm{min}\right)$ from 25 to $1200^{\circ} \mathrm{C}$ under air atmosphere $(15 \mathrm{ml} / \mathrm{min})$ (Figure 6).

\section{Results and Discussion}

\subsection{X-Ray Diffraction of $\mathrm{PbSO}_{4}$ and Lead Oxide Sulfate $\mathrm{PbSO}_{4} \cdot \mathrm{PbO}$}

The both Figures $1 \& 2$ show the experimental XRD results of both above mentioned compounds. These results correspond to standard diagrams (ASTM: 36-1461 and 33-1486).

\subsection{Electron Micrographs Investigations of $\mathrm{PbSO}_{4}$ and $\mathrm{PbSO}_{4} \mathrm{PbO}$}

As indicated from Figure 3, crystals are round and hexagonal with a diameter of 1 to $10 \mu \mathrm{m}$, the reasonable enlargement in SEM photographs was 3000 times. They are arranged well next to each other and form large round crystals. Figure 4 shows the SEM photographs of $\mathrm{PbSO}_{4} \cdot \mathrm{PbO}$. As we can see_large crystals was formed in the form of long and laminar texture. These crystals have a length of ca. $300 \mu \mathrm{m}$ and a diameter of about $20 \mu \mathrm{m}$. The reasonable enlargement in SEM photographs was 200 times. In addition to the large crystals can be seen even small crystals, which have a diameter of about $5 \mu \mathrm{m}$.

Figure 5 shows TEM photographs of $\mathrm{PbSO}_{4} \cdot \mathrm{PbO}$. The crystals are somewhat larger, they form also small

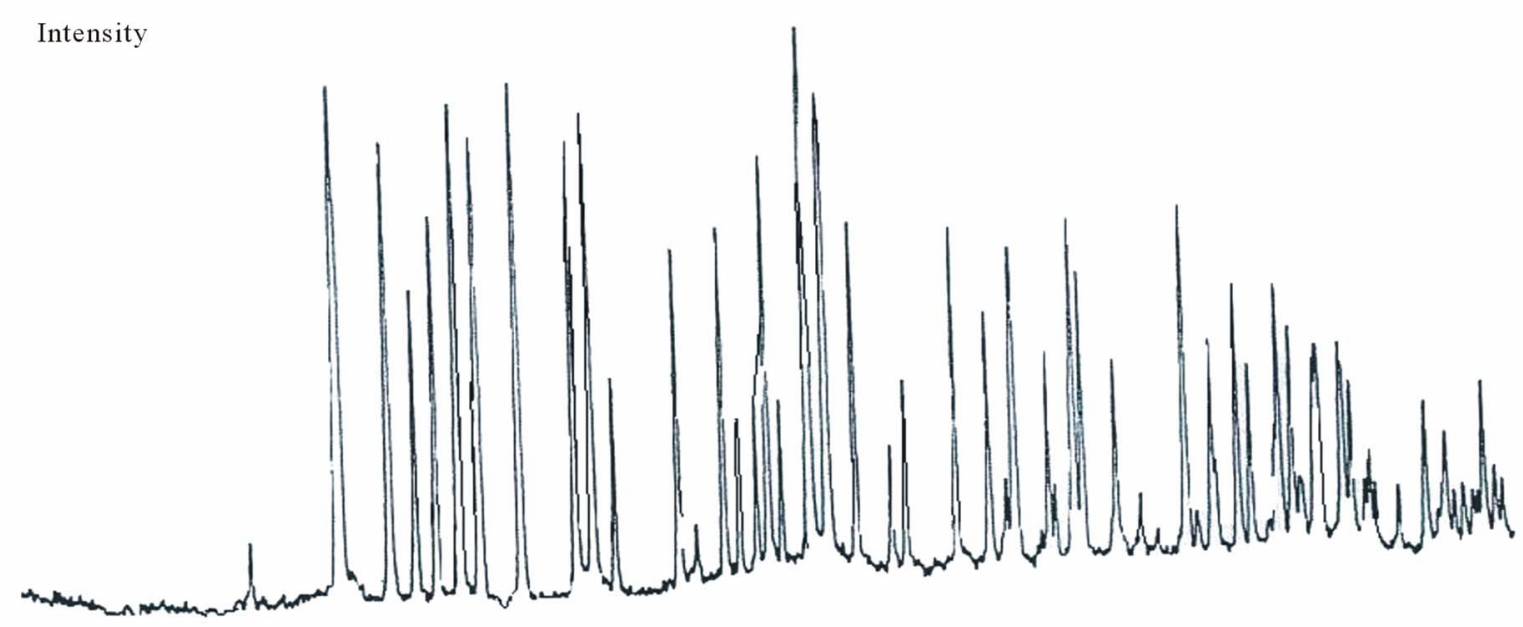

Figure 1. XRD diagram of $\mathrm{PbSO}_{4}$. 


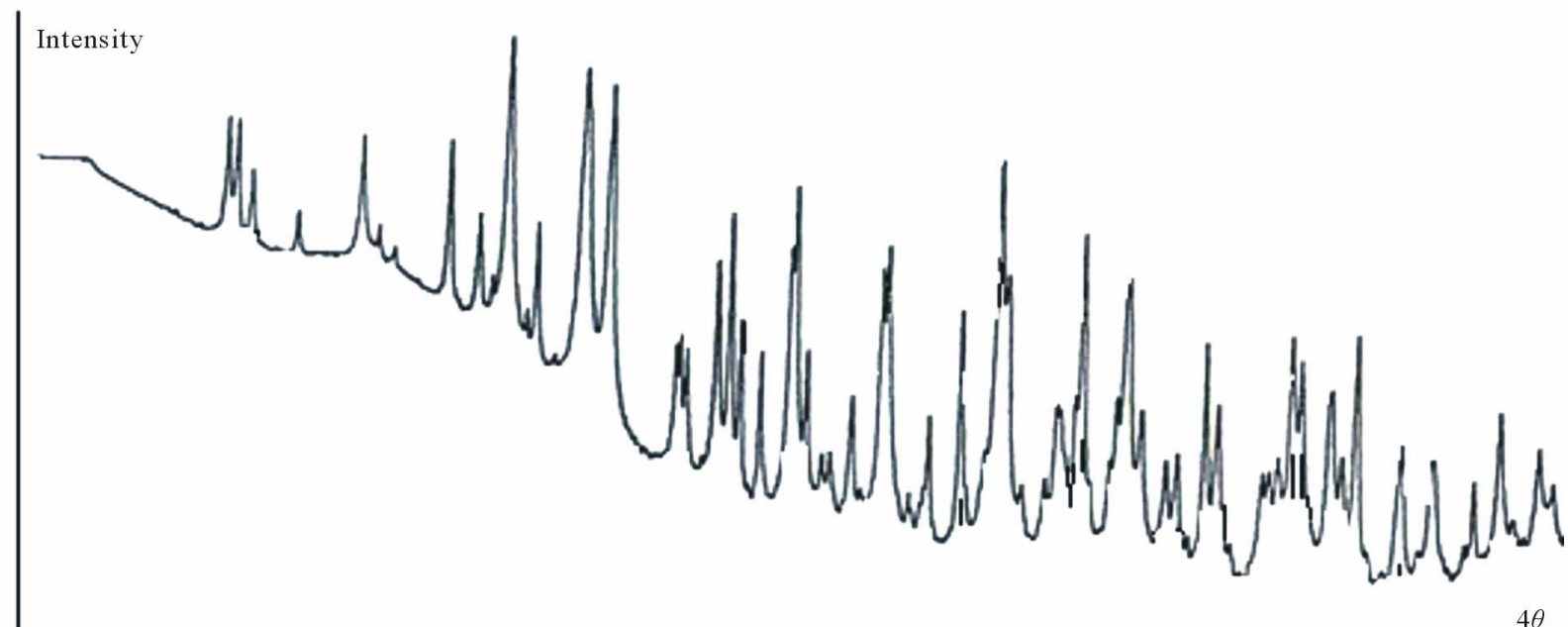

Figure 2. XRD diagram of $\mathrm{PbSO}_{4}{ } \mathrm{PbO}$.

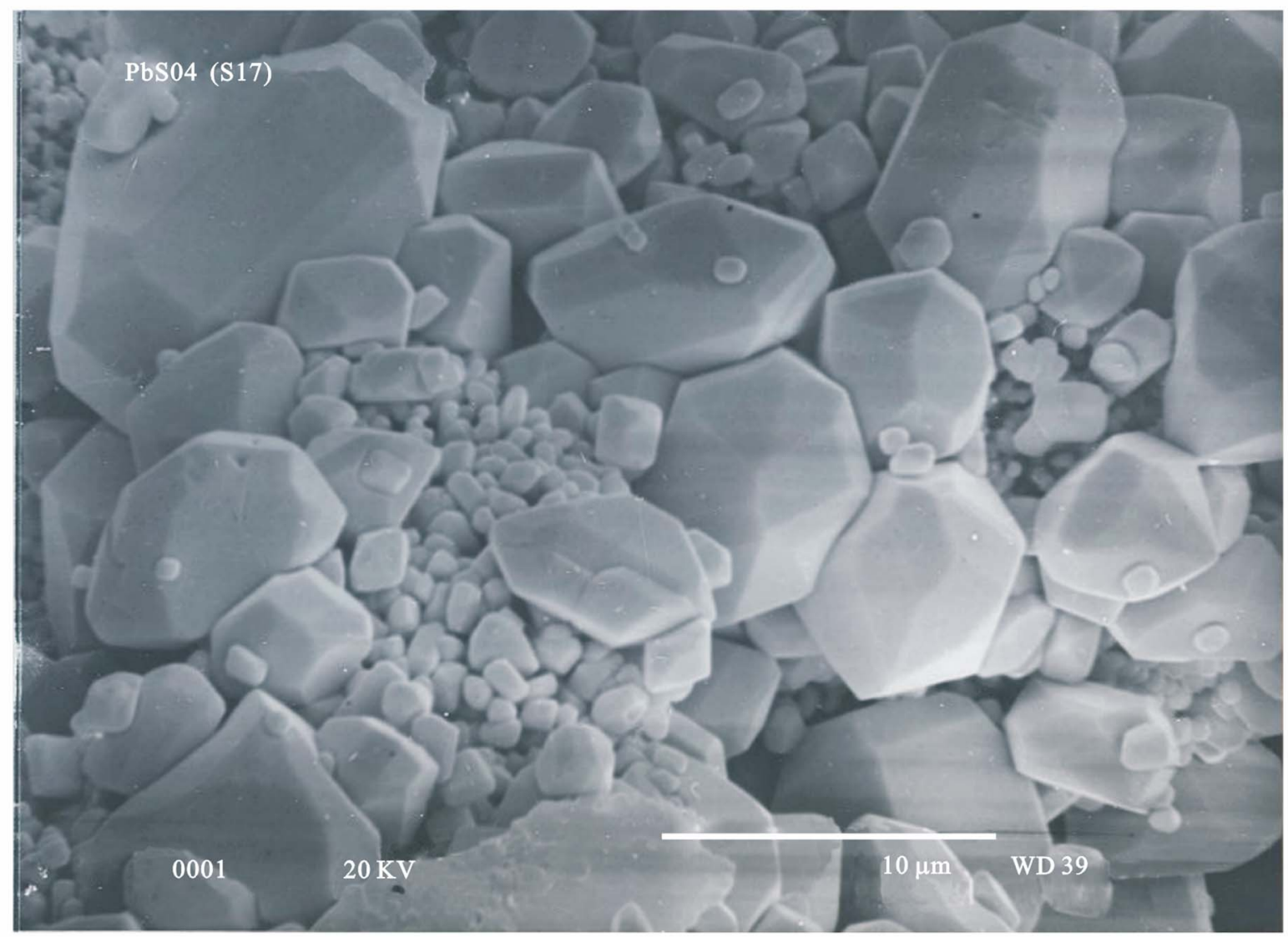

Figure 3. SEM electron microscopic photograph of lead sulfate, enlargement is $3000 \times$.

crystals. Individual particles look angular and hexagonal and can be observed in small and larg of dimensions. Apart from brocken crystals they are mainly arranged crystals. The reasonable enlargement in TEM photographs was 20,000 times.

\subsection{Thermal Investigations of Lead Sulfate $\mathrm{PbSO}_{4}$}

TGA-results:

TGA curve of thermal decomposition of $\mathrm{PbSO}_{4}$ is 


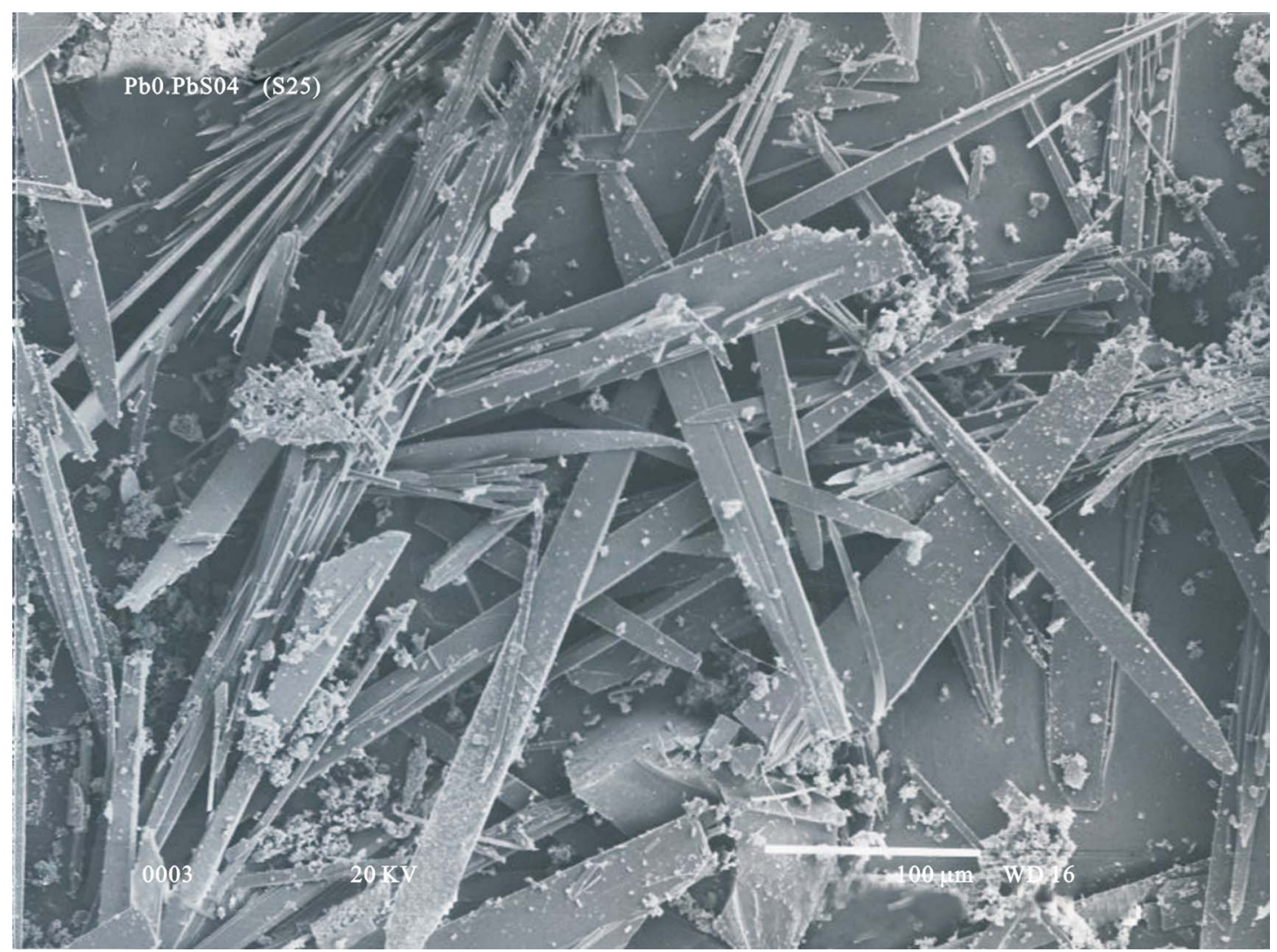

Figure 4. SEM electron microscopic photograph of $\mathrm{PbSO}_{4} \cdot \mathrm{PbO}$, enlargement is $200 \times$.
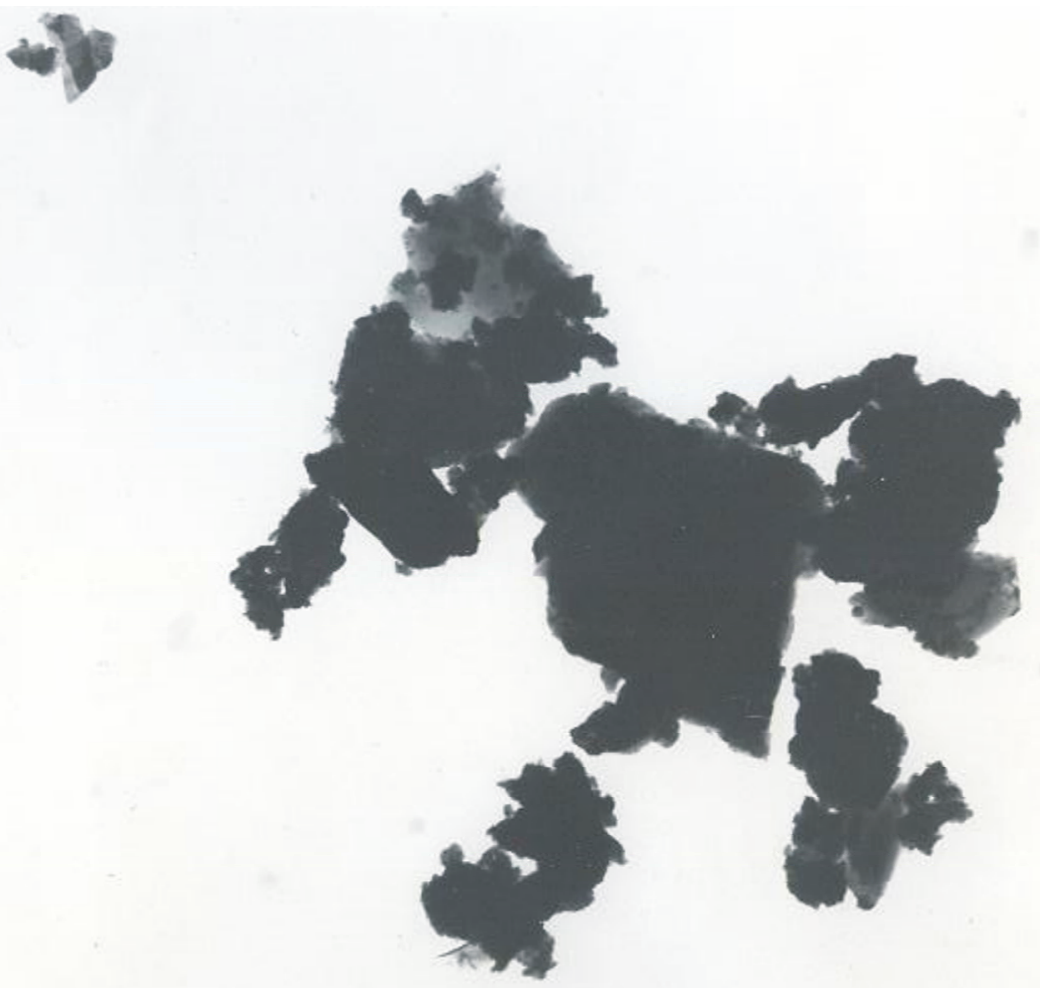

Figure 5. TEM electron microscopic photograph of $\mathrm{PbSO}_{4} \cdot \mathrm{PbO}$, enlargement is $20000 \times$. 
shown in Figure 6. The curve shows the weight loss (vertical axis) versus increase in temperature (horizontal axis).

The results indicate thermal decomposition consists of two subsequent stages in the temperature range of $880^{\circ} \mathrm{C}$ - $1200^{\circ} \mathrm{C}$ and summarized in Table 1.

The first stage takes place between $886^{\circ} \mathrm{C}-1142^{\circ} \mathrm{C}$. The regarding calculations of weight loss are reported.

The computed stoichiometry of decomposition products are in good agreement with experimental results (quantitative and percent decrease in weight).

1) First \& second points o TGA curve $\left(25^{\circ} \mathrm{C}-886^{\circ} \mathrm{C}\right)$

A heating rate of $5^{\circ} \mathrm{C} / \mathrm{min}$ was chosen to determine the real value of adsorbed quantity of water as well as finding out more information on what is taking place in this temperature range. The experiment was accomplished in the air atmosphere with a constant gas flow of 15 $\mathrm{ml} / \mathrm{min}$.

In these two temperatures range i.e., points $1 \& 2$ we consider no significant weight decrease. In other words it takes place no reaction.

2) Third \& fourth points of TGA curve $\left(886^{\circ} \mathrm{C}-1200^{\circ} \mathrm{C}\right)$

In the temperature range of $886^{\circ} \mathrm{C}-1142^{\circ} \mathrm{C}$ we consider weight loss equal to about $89.19 \%$ starting material and occur in the temperature range of $886-1142^{\circ} \mathrm{C}$. The $\mathrm{X}$-ray analysis of the product confirms presence of $\alpha-\&$ $\beta$-PbO. This was checked by spectrometric analysis and the calculated brutto formula of $\mathrm{PbO}$ is reached.

We want to point out again that the pyrolysis of $\mathrm{PbSO}_{4}$ within the range $886^{\circ} \mathrm{C}-1142^{\circ} \mathrm{C}$ in the air atmosphere led to $\mathrm{PbO}$, i.e. the reaction $\mathrm{PbSO}_{4} \rightarrow \mathrm{PbO}$ ran off completely with approximately $1100^{\circ} \mathrm{C}$. From the above TG diagram it is evident that the pyrolysis reaction of $\mathrm{PbSO}_{4}$ in the range $886^{\circ} \mathrm{C}-1142^{\circ} \mathrm{C}$ consists of two stages. The final decomposition product is $\mathrm{PbO}$.

Therefore, study of thermal Behavior of $\mathrm{PbSO}_{4}$, by Thermogravimetry suggests four different stages as discussed above. At first the compound losses $\mathrm{SO}_{3}$ followed

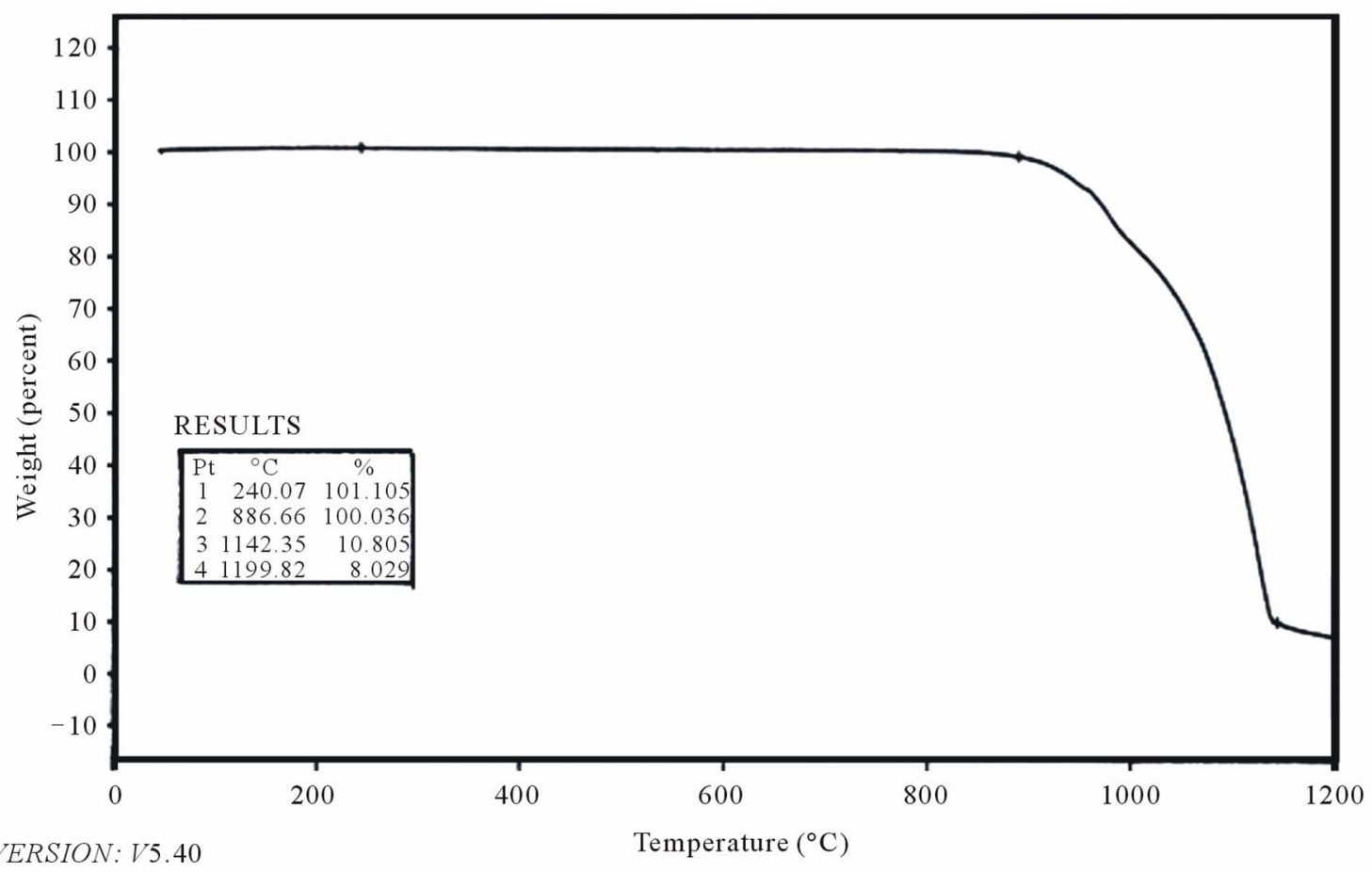

Figure 6. TGA diagram of lead sulfate $\left(\mathrm{PbSO}_{4}\right)$.

Table 1. Results from the thermal investigations of $\alpha-\mathrm{PbO}_{2}$ in temperature range $25^{\circ} \mathrm{C}-1200^{\circ} \mathrm{C}$ in air atmosphere.

\begin{tabular}{|c|c|c|c|c|}
\hline Point No. & $\begin{array}{c}\text { Start temp. } \\
{\left[{ }^{\circ} \mathrm{C}\right]}\end{array}$ & $\begin{array}{c}\text { End temp. } \\
{\left[{ }^{\circ} \mathrm{C}\right]}\end{array}$ & $\begin{array}{c}\text { Weight decrease } \\
{[\mathrm{mg}]}\end{array}$ & $\begin{array}{c}\text { Weight decrease } \\
{[\%]}\end{array}$ \\
\hline 1 & 25.0 & 240.7 & $\sim 0$ & $\sim 0$ \\
\hline 2 & 25.0 & 886.7 & $\sim 0$ & $\sim 0$ \\
\hline 3 & 25.0 & 1142.4 & 7.311 & 89.19 \\
\hline 4 & 25.0 & 1199.6 & 7.539 & 91.97 \\
\hline
\end{tabular}


by evaporation of $\mathrm{PbO}$ in the approximately temperature range of $1100^{\circ} \mathrm{C}$ to $1200^{\circ} \mathrm{C}$. We are not able to consider these two phenomenons separately because these two reactions overlap each other.

\section{Conclusions}

It was clearly stated that the final product consists only of $\alpha$ - and $\beta$-PbO, which was a good result. The chemical analysis showed no impurities. The thermal investigations of $\mathrm{PbSO}_{4}$ by TG method showed that under air atmosphere the compound decomposes to $\alpha$ - and $\beta$-PbO. Since $\mathrm{PbO}$ does not contain impurities, one can reuse in the industry. Lead sulfate can be converted to $\mathrm{PbO}$ in industry which is an economical procedure.

\section{References}

[1] E. W. Able, "Comprehensive Inorg," Chemistry, Vol. 2, 1973, pp. 105-146.

[2] Ullmann (5.Auflage), Lead Alloys \& Lead Compounds, Vol. A15, 1990, pp. 193-257.

[3] Gmelin, Lead Syst., No. 47, 1978.

[4] R. Giovanoli and R. Brutsch, Chemia, Vol. 32, 1978, pp. 257-259.

[5] R. Glemser, Zeitschrift für anorganische und allgemeine Chemie (ZAAC), Vol. 244, B382, 1971.

[6] E. Preisler, "Semiconductor Properties of Manganese Dioxide," Journal of Applied Electrochemistry, Vol. 6,
1976, pp. 311-316 doi:10.1007/BF00608916

[7] N. Greenwood, Chemie der Elemente, Verlagsgesellschaft VCH, 1988, pp. 440-453.

[8] S. A. A. Sajadi and S. J. Hashemian, "Synthesis of Lead (IV) Oxides and Investigation to Thermal Properties," Journal of Science, A.Z.U., Vol. 14, No. 2, 2001, pp. 25-31.

[9] S. A. A. Sajadi, Scientific Soc. Appl. Chem., Vol. 8, 2001, pp. 1-6.

[10] S. A. A. Sajadi, J. Science, T.U., Vol. 2, 2002.

[11] S. A. A. Sajadi and S. J. Hashemian, Sharif J. Science \& Technology, Vol. 29, 2005, pp. 57-62.

[12] E. Mueller, Zeitsch. F. Phys. Chem, Vol. 114, 1925, pp. 129-156.

[13] H. Mauch, "Über ein neues Bleihydroxycarbonat," Helvetica Chimica Acta, Vol. 11, 1957, pp. 86-87. doi:10.1002/hlca.19570400109

[14] S. A. A. Sajadi and A. A. Alamolhoda, "Synthesis and Properties of Lead Oxide Carbonate," Inorganic Materials, Vol. 42, No. 10, 2006, pp. 1-5. doi:10.1134/S0020168506100098

[15] S. A. A. Sajadi, A. A. Alamolhoda and S. J. Hashemian, "An Investigation into the Structure and Thermal Properties of Lead Hydroxide," Scientia Iranica, Vol. 14, No. 2, 2007, pp. 169-173.

[16] R. Kuhn and I. Hammer, Chem. Ber. Vol. 83, 413, 1950. 